\title{
The Friendships of Racial-Ethnic Minority Youth in Context
}

\author{
To appear in \\ Handbook of Positive Development of Minority Children \\ Editors: Natasha J. Cabrera and Birgit Leyendecker \\ Section Editor: Christiane Spiel
}

Leoandra Onnie Rogers

University of Washington

Erika Y. Niwa

Brooklyn College, CUNY

Niobe Way

New York University

Rogers L.O., Niwa E.Y., Way N. (2017) The Friendships of Racial-Ethnic Minority Youth in Context. In: Cabrera N., Leyendecker B. (eds) Handbook on Positive Development of Minority Children and Youth. Springer, Cham

https://doi.org/10.1007/978-3-319-43645-6_16 


\begin{abstract}
An extensive theoretical and empirical literature suggests that friendships are an important, if not essential, micro-context of adolescent development - shaping youth identity, school and civic engagement, and psychological and physical wellbeing. Friendships are also themselves embedded within, and shaped by, the larger macro-context of culture (Bronfenbrenner, 1979), including racial-ethnic stereotypes (García-Coll et al., 1996; Spencer, 1995). Yet, the study of friendship rarely examines the influence of the macro-context or includes racial-ethnic minority youth despite the fact that such youth represent half of the American youth population. In this chapter, we review research on the friendships of racial-ethnic minority youth and focus specifically on how the macro-context of social-identity based stereotypes shapes the microcontext of friendships.
\end{abstract}




\section{The Friendships of Racial-Ethnic Minority Youth in Context}

Human beings are innately designed for relationships. The ability to relate to another person, to feel empathy and intimacy, is a defining feature of being human, and our innate desire for relationship shapes every aspect of who we are and become (Bond, 2013; Bowlby, 1969/1982; Chu, 2014; de Waal, 2006; Gilligan, 1982, 2011; Hrdy, 2009; Travarthan, 1979; Way, 2011). Decades ago, Harry Stack Sullivan (1953) argued that friendship - that intimate emotional bond with one's age peers - was the chief source of a child's sense of security, selfworth, and wellbeing. Our relational nature, furthermore, does not exist in a vacuum. Who we befriend and how we experience those relationships are shaped by the norms, expectations, and stereotypes of the context and culture in which we are embedded. In a socially stratified society, youth are shaped by their "social address" - their ethnicity/race, gender, and nationality - and the beliefs that accompany these social positions (García Coll et al., 1996; García Coll \& Szalacha, 2004; Spencer, 1995; Spencer, Dupree, \& Hartmann, 1997). While a vast empirical literature documents the consequences of friendships for adolescents' social, emotional, and cognitive development and adjustment (see Rubin, Bukowski, \& Larson, 2009 for review), it rarely attends to the ways the social ecology shapes friendships or the experiences of racial-ethnic minority youth. (For exceptions see: Azmitia \& Cooper, 2001; Cauce, 1986; Graham, Taylor, \& Ho, 2009; Way, Becker, \& Greene, 2006; Way \& Chen, 2000; Way \& Silverman, 2011; Way, 2011).

In this chapter, we employ an ecological lens (Bronfenbrenner, 1979; García Coll et al., 1996; Spencer, 1995) to understand friendships among racial-ethnic minority youth living in the United States. We utilize data from our research with ethnically diverse American adolescents, collected over the past two decades, to reveal the ways in which the macro-context of ethnic, racial, gender, and sexuality stereotypes shapes the quality and experience of adolescents' 
friendships (e.g., Niwa et al., 2010; Niwa, 2012; Rogers, 2012; Rogers \& Way, 2015; Way, 2011; Way, Santos, Niwa, \& Kim-Gervy, 2008; Way, Hernandez, Rogers, \& Hughes, 2013; Way \& Rogers, 2014). In this chapter, we first discuss the ecological framework used in our analysis and then review existing research on the friendships of racial-ethnic minority youth. In the remainder of the chapter, we use empirical examples from our research, as well as others, to illustrate the ways that stereotypes shape friendships via two interrelated paths: peer discrimination and identity development.

\section{HISTORICAL OVERVIEW/THEORETICAL PERSPECTIVES}

\section{An Ecological Model of Adolescent Development}

An ecological approach to human development assumes that the individual is dependent upon and inextricable from the environment around him or her (Bronfenbrenner, 1979; Bronfenbrenner \& Morris, 1998). Bronfenbrenner's bioecological model contends that development is the result of a dynamic transactional relation between individuals and their environment(s). These reciprocal interactions "are posited as the primary engines of human development" (Bronfenbrenner \& Morris, 1998, p. 798) in which the unit of analysis is not only the person her or himself but also how the context shapes that person's experiences. The environment is operationalized as nested systems that include the micro- and meso-systems as those most proximal to the individual and the exo-and macro-systems that are more distally situated (Bronfenbrenner, 1979). The micro-system is marked by ongoing exchanges that occur within the immediate contexts of home, family, school, and neighborhood, and the meso-system consists of the reciprocal interactions between the people in those environments: parents, teachers, and peers. The exo-system refers to those contexts in which the individual is not directly located but impact the child's development nonetheless, such as parents' workplace. 
Finally, the macro-system includes the larger cultural norms, stereotypes, beliefs, expectations and practices as well as governmental laws - all of which impact both the structure and function of settings (e.g., schools), as well as relational dynamics within those settings. An important assumption of the ecological model is that these systems function jointly. As such, the macrosystem impacts the individual via the processes that operate within the micro- and meso-systems. Thus, it is through relationships, such as friendships, that values from the macro-system are manifested, enacted, and experienced.

Two key scholars have extended Bronfenbrenner's ecological systems theory to address the ways in which social status and power influence the dynamics of the ecosystem: García Coll's integrative model of development (1996) places beliefs systems about race, ethnicity, and class at the center of her ecological theory and asserts that developmental processes are deeply affected by a child's social position or "social address" (e.g., race/ethnicity, gender) within a social-stratified society (García Coll \& Szalacha, 2004). Social position, according to García Coll, gains meaning through the macro-context and has a direct and indirect effect on individual development as well as the micro-contexts. Yet it is not the social position per se that influences development but the cultural meaning associated with that position which influences developmental processes. In other words, it is the stereotypes, norms, and expectations about race-ethnicity that shape development rather than the social positions themselves (SanchezJankowski, 1992; Suarez-Orozco, 2004).

While García Coll's (1996) model emphasizes how the meaning of a social position is shaped by the context, Spencer's (1995) P-VEST (Phenomenological Variant of Ecological Systems Theory) incorporates inter-subjective experience to focus on how adolescents process or make sense of their social positions. P-VEST asserts that “... the individual's ability to 
understand societal expectations, stereotypes and biases - even those that they themselves endorse or fulfill" frames their experiences within and responses to the context (Gordon \& Gergen, 1968; Spencer, et al., 1997, p. 818). In this way, P-VEST asserts the role of identity as a mechanism through which the macro-context is manifested at the level of individual development. Race-ethnicity, then, is a lens through which adolescents experience the world shaping how they see themselves (i.e., identity) and engage with others (i.e., their friendships).

Taken together, ecological systems theory and its theoretical extensions highlight three relevant points in the examination of adolescent friendships. First, contexts make indelible imprints on the relationships that youth develop and experience. Second, socio-historical and cultural forces alter the very geography of adolescents' relationships. Finally, explorations of adolescent friendships should include the perceptions of the adolescents themselves, who are active agents in their own development.

\section{Friendships among Racial-Ethnic Minority Youth}

Sullivan (1953) theorized that establishing close and intimate connections with peers or "chums" during adolescence is essential for psychological and emotional development, for “... it is during this period that a child begins to develop a real sensitivity to what matters to another person (p. 245)." In other words, friendships or "chumships" lay the groundwork for social skills, while also providing opportunities for self-worth and a blueprint for romantic relationships. Empirical research on American adolescents' friendships has primarily assessed friendship quality (e.g., intimacy, affection, companionship, satisfaction) and how friendship quality is linked to adolescent adjustment (see Bukowski, Newcome, \& Hartup, 1996; Furman, 1996; Rubin et al., 2009). Decades of theory and research demonstrate the impact of friendships on a range of social, academic, and cognitive outcomes. Adolescents who report higher quality 
friendships report better psychological wellbeing, academic performance, social skills, and health (Berndt, 2004; Crockett, Losoff, \& Petersen, 1984; Csikszentmihalyi \& Larson, 1984; Hartup, 1996; Osterman, 2000; Rubin et al., 2009; Savin-Williams \& Berndt, 1990; Way, 2011). Although friendships appear to be critical for all adolescents (Berndt, 2004; Hinde, 1987; Petterson, Dishion, \& Yoerger, 2000), the majority of the research has been conducted with White, middle-class, American adolescents. In fact, a recent content analysis of the friendship literature found that less than $7 \%$ of the studies on friendships referenced racial-ethnic minority adolescents (Graham et al., 2009). However, 37\% of the U.S. population is of ethnic minority status (Latinos, Asians, Blacks; Pew Research Center, 2014), and in the last decade, from 2000 to 2010 , ethnic minorities accounted for $91.7 \%$ of America's total population growth (Pew Research Center, 2011). This increase is concentrated among youth as half (50.3\%) of students enrolled in American public schools are ethnic minorities (Pew Research Center, 2014). These demographics raise concerns about the generalizability of research findings based on White, middle-class youth to any youth outside of those demographic categories, including racial-ethnic minority, immigrant, non-American, or poor and working-class adolescents.

The literature that has included racial-ethnic minority adolescents focuses mostly on ethnic differences or specific topics within the study of friendships. For example, studies find ethnic differences in the importance of friendships (e.g., Gupta \& Sirin, 2010), levels of friendship quality (e.g., Azmitia \& Cooper, 2001; Azmitia, Ittle, \& Brenk, 2006; Jia et al., 2009; Way et al., 2006), and friendship support (e.g., Kao \& Joyner, 2004; Way \& Chen, 2000; Way \& Greene, 2006). The study of cross-race friendships, which necessarily includes racial-ethnic minority youth, suggests that adolescents prefer same-race friends (DuBois \& Hirsch, 1990; Hamm, Brown, \& Heck, 2005; Mouw \& Entwisle, 2006) and that cross-race friendships tend to 
be less stable over time (McGill, Way, \& Hughes, 2012). Research on peer social status suggests that White students garner popularity for prosocial behaviors (being cooperative and cool) whereas African American students (particularly boys) are esteemed for tough, aggressive and antisocial behaviors (e.g., Luther \& McMahon, 1996; Rodkin, Farmer, Pearl, \& Van Acker, 2000). The study of antisocial or delinquent peer groups similarly focuses mostly on African American boys, in particular, who are disproportionately labeled as aggressive by adults and peers and suspended and expelled for behavioral problems (e.g., Noguera, 2008). Prior studies find that youth with more antisocial friends exhibit more antisocial behaviors (e.g., Dodge, Coie, Lynam, 2006), due to process called "deviancy training" whereby youth "train" their peers in rule breaking and bad behaviors to solidify a delinquent peer culture (Dishion \& Piehler, 2009). Interestingly, in a study of adolescents' susceptibility to such negative peer pressure, or deviancy training, Steinberg and Monohan (2007) found that African American adolescents were actually the most likely to resist the influence of negative peers compared to other racial-ethnic groups.

Other friendship research involving racial-ethnic minority youth examines how different levels of context (e.g., family, school) shape friendship processes. For example, in terms of the family context, research suggests that maternal support or acceptance of one's friends is strongly associated with more positive friendship quality (Updegraff, McHale, Crouter, \& Kupanoff, 2001; Way \& Silverman, 2011; Way, 2011). In a longitudinal analysis of friendship quality, Way and Greene (2006) found that adolescents who reported the lowest levels of maternal support reported the sharpest increases in friendship support over time, indicating that the family context significantly impacts adolescents' friendships. Parents' attitudes are also predictive of the quality of adolescents' friendships, where supportive parental attitudes predict more positive friendship quality over time (Way \& Silverman, 2011; Way 2011). Yet, the influence of parental attitudes 
towards friendships varies across cultures and cultural variations in parenting beliefs and practices impact how adolescents experience their friendships (e.g., Gupta \& Sirin, 2010). The school context also impacts adolescents' friendships. For example, positive school climate and sense of belonging shapes not only adolescents' own self-perceptions (identity) but also their social interactions and relationships (Crosnoe, Cavanagh, \& Elder, 2003; Eccles \& Roeser, 1999). In hostile school environments, adolescents are less likely to develop positive and supportive friendships (Crosnoe et al., 2003), and school-level practices that reify stereotypes (e.g., tracking) disrupt positive peer relationship and incite peer discrimination (e.g., Lei, 2003; Rosenbloom \& Way, 2004). Studies of cross-race friendships also note the relevance of context, finding that the likelihood of cross-race friendships is "opportunity-based" - youth in more diverse schools are more likely to befriend peers from a different ethnic-racial group (e.g., Hallinan \& Teixeira, 1987; Moody, 2001). At the same time, other ecological factors, such as ability tracking, instructional practices, and teacher expectations, can disrupt these opportunities. For example, Hallinan and Williams (1987) found that cross-race friendships between Black and White students were significantly less likely when teachers structured their classroom and instructional practices around levels of academic achievement (e.g., ability grouping).

While prior studies highlight relevance of ecological factors in adolescents' friendships, the study of context has been largely limited to the meso-system (family or schools) with little attention given to the mechanisms through which macro-cultural forces, such as stereotypes and expectations, impact the friendships of American racial-ethnic minority adolescents.

\section{Stereotypes and Adolescent Friendships}

Stereotypes are widely held cultural beliefs and expectations, generalized attitudes or evaluations about individuals who share a social address or position, such as ethnicity, race, 
gender, social class, or nationality (Stangor \& Schaller, 1996). They offer a lens through which one can observe the impact of macro level forces on micro level contexts such as friendships. African-American adolescents are stereotyped as rhythmic and athletic, but also lazy and dumb. Black males, specifically, are stereotyped as violent, aggressive, and hypersexual whereas Black females are stereotyped as overweight, loud and angry (Fordham, 1993; Ghavami \& Peplau, 2013; Stevenson, 1997). Latino males are similarly stereotyped as lazy and dumb, as well as gangsters and drug lords while Latinas are stereotyped as the hyper-sexualized "mamasita" (López, 2003). Asian-American youth, in contrast, are stereotyped as "model minorities"smart, quiet, and obedient (Lee, 1994; Lei, 2003), but also weak and feminine (Lei, 2003; Ghavami \& Peplau, 2013). At the same time, Asian immigrant youth are viewed as dirty and poor (Chua \& Fujino, 2008; Lei, 2003; Shek, 2006). Notably, stereotypes are not limited to ethnic minorities. Whites are stereotyped as wealthy, smart and successful, but also weak, "soft," or gay (Ghavami \& Peplau, 2013; Pascoe, 2007). Such stereotypes make up the very "fabric of the [American] society" (Stangor \& Schaller, 1996, p. 10).

Stereotypes are inherently relational, such that beliefs about one group are defined in relationship to another (Lesko, 2001; Nasir, 2011). For example, “acting Black” refers to speaking in slang, dressing in urban style, and listening to hip hop music (Carter, 2006), whereas "acting White" refers to speaking proper English and excelling in school (Fordham \& Ogbu, 1986; Carter, 2006). Nasir and Shah (2011) describe these racial and ethnic contrasts in this way: As with 'Asians are good at math', the notion that 'White men can't jump' exemplifies how racialized narratives tend to be inherently relational in character. The inability of White men to jump is only visible because of the (presumed) certainty that non-White men (usually African American men) can jump (p. 30). 
Stereotypes, then, not only shape how youth see themselves, but also how they see others.

Adolescents from different racial-ethnic groups encounter unique yet related cultural ecologies in the form of stereotypes that shape all aspects of youth development, including peer interactions.

\section{CURRENT RESEARCH AND METHOD}

The data we present in this chapter come primarily from the studies with raciallyethnically diverse American adolescents conducted by Niobe Way and her students over the past 20 years, and the dissertation research conducted independently by Onnie Rogers. We draw from

four longitudinal mixed-method studies involving, in total, over one thousand youth attending six middle schools and three high schools located in two cities in the United States. Our samples include: African-American, European-American, Chinese-American, Dominican-American, and Puerto Rican adolescents, most of whom attended schools where the majority of the students qualified for the free/reduced lunch program.

The first two projects, Connections and Relationships Among Peers (RAP), were conducted by Niobe Way and funded by the National Science Foundation and The William T. Grant Foundation. These longitudinal studies took place in a co-educational high school in a city in the Northeast, and focused on adolescents' identity development and friendships. The third project, called Project $R A P$, was another longitudinal project conducted by Niobe Way and Diane Hughes at the Center for Research on Culture, Development, and Education at New York University and was funded by the National Science Foundation ${ }^{1}$. This project was a six-year longitudinal project that included 6 middle schools with a total of 1,034 students involved in the survey component and 250 students and their mothers in the interview component that took place from $6^{\text {th }}$ through $11^{\text {th }}$ grade (for more information about the samples, see Niwa, Way, \& Hughes,

\footnotetext{
${ }^{1}$ National Science Foundation (NSF) grant number: 021859
} 
2014; Rogers \& Way, 2015; Way et al., 2008; Way, 2011). The project focused on the ways in which the contexts of school, families and peers, shape the social, emotional, and academic development of ethnically diverse urban youth. Lastly, The Identity Project, funded by The Spencer Foundation, was a two-year mixed-method study conducted by Onnie Rogers at an allBlack, all-male high school in a city in the Midwest. The Identity Project used in-depth interview, survey and observation methods to examine adolescent racial and gender identity development.

Our research repeatedly demonstrates that racial-ethnic, gender, and sexuality stereotypes are salient and integral in adolescents' daily experiences and interactions with friends (Niwa, Way, \& Hughes, 2014; Niwa, Way, Okazaki \& Qin-Hilliard, 2011; Rogers, 2012; Rogers \& Way, 2015; Way \& Rogers, 2014; Way, et al., 2008; Way, et al., 2013; Way, 2011). These processes are evident in adolescents' friendships through peer discrimination and identity development.

\section{Peer Discrimination}

Prior research, including our own, suggests that adolescents use stereotypes to exclude and discriminate against peers in order to maintain cultural norms. For example, Pascoe's (2007) ethnography of masculinity in an urban high school shows how boys enforce masculine stereotypes in their friendships by excluding boys who deviate from masculine norms. Such boys were teased, rejected and sometimes permanently banned from the group because their actions posed a threat to maintenance of masculine norms - tough, crass, athletic, funny, troublemakers. In an analysis of gender, race and schooling, Davis (2001) finds that "Black boys who do not meet the standards of an acceptable masculinity are treated as masculine mistakes," they are teased by their peers, called "gays" and "sissies," and relegated to socialize with girls (p. 147). Studies on the "acting white" phenomenon (Carter, 2006; Fordham \& Ogbu, 1986; Horvat \& O’Connor, 2006) similarly reveal how peers may police the cultural boundaries about what it 
means to be (and not to be) Black. "Acting white" is set of norms about how one ought to behave (e.g., carry him/herself, dress, speak) given his or her racial-ethnic group that functions to discriminate against certain peers thereby structuring adolescents' friendships.

In Rogers' dissertation study with Black adolescent males attending an all-Black male high school, she finds that stereotypes about race, gender, and sexuality structured the friendship dynamics within the school (Rogers, 2012). Many of the boys indicated that simply attending an all-male school was "gay." Teddy (African-American) explained that he did not want to attend the all boys' school '[Be]cause I heard a lot of stuff about all boys schools. ...People turn gay. That's what I heard." Brandon (African-American) explained that there was a "good side and a bad side" to attending an all-boys' school and the bad side is "that people be thinkin' you gay or something like that. Yeah, a lot of guys I know be thinkin' that's gay." In this context, boys avoided other boys who "acted feminine" and used homophobic language to assert their heterosexual identities and maintain boundaries between themselves and the boys who "acted feminine” (Rogers, 2012). For example, Kirk (African-American) said:

I mean, dudes play around in this school, they go around tappin' other dudes on the butt and stuff like that. I just try to stay away from that stuff. It's just disgusting...It's just - I don't think I'm homophobic it's just that kind of stuff bothers me ... \{laughter\} I kinda, I just get up and move. I try to just keep 'em over there.

Illustrating how stereotypes were used to draw friendship boundaries, Brandon (AfricanAmerican) explained: “It ain't none of my business I just stay out of it, I'll be like, that's your all opinion. They just stay together. They mind their business, the others mind theirs, I mind mine.” Lewis (African-American) also explained:

Like we're all friendly and stuff... But we still keep it low because we just don't talk 
about other gay people; we don't do that unless they make us mad or keep on coming by us. But basically, they keep their distance and we keep our distance. They mind their business and we mind ours.

In other words, stereotypes about (Black) males' sexuality and how they "should act" were used to exclude particular students and therefore structure their friendship opportunities.

Even for boys who were not blatantly homophobic, the context of stereotypes actively shaped which peers boys interacted with and the quality of those friendships. For example, Devin (African American) explained that the expectation for boys "to act more masculine...I guess you could say like straight..." was used in the school to exclude peers who did not conform:

I mean we have some feminine guys here at the school. I've got one in my [class] and he's gay, you know. I'm not going to say any names, but I'm just saying I don't have anything against him. I talk to him and he's a cool guy, like he ain't stereotypically all gay. You know, oh you can't even talk to them [gay students] without them thinking about boys and that they just want to go with you; that's why some dudes don't talk to them. But he's just like a regular dude. You know, he's gay; he just acts cool.

Devin is acutely aware that "feminine behavior" is problematic for boys, and he feels the need to protect the identity of his gay friend ("I'm not going to say any names"). But Devin also protects himself, explaining that he sometimes "ignores" this friend who is gay by keeping his distance: I mean, I don't hang around him like all the time, you know, I say what's up to him and all that stuff. I don't just like chill with him, you know. But I say hey what's up, you know and I'm cool with him...

Even though Devin challenges the idea that he needs to completely avoid feminine boys, the stereotype still significantly shapes his friendship. 
In Way's studies of racial-ethnic minority adolescents in co-educational and diverse school contexts, we similarly find that stereotypes are used to exclude peers and structure adolescents' friendships (e.g., Niwa et al., 2014; Way et al., 2008; Niwa et al., 2011; Way, 2011). For example, Patricia (Dominican-American) described the "ghetto kids" in a clique at her school as "Spanish and Black people that are in gangs and people that do drugs" and "beat you up." Abel (Dominican-American) said: "one time, some kid was calling me 'Spanish boy, Spanish boy!'...I think he just hates Latino kids." In contrast, the Chinese-American students were described by their peers (as well as by themselves) as "weak" and "nerdy," and, as a result, were often victimized by their peers (e.g., Niwa, 2012; Niwa et al., 2011; Way et al., 2008). For example, Henry (Chinese-American) described the "nerdy Chinese students": "They're weird. They know everything...All of them have glasses... Like math questions, they will always know it ...They're smart." These stereotyped descriptions facilitated peer discrimination: "They call the Chinese kids nerds and chinks...they call them chinks." Other students similarly shared examples of racial slurs based on stereotypes. Judy (Chinese-American) explained: "Sometimes people would bully us in school, like not bully, but like say really racist things about Chinese people." In these examples of peer discrimination, stereotypes, or "racist things" are used to exclude, isolate, and victimize thereby shaping adolescents' friendship experiences.

Other students described experiences of implicit discrimination. For example, Cira (Dominican-American) said "since I'm a Dominican [other students] think I'm not going to be as smart as they are." She offered an example from math class:

Um, two weeks ago or something...we had to measure apartments and we had to do the dimensions and stuff. And I was going to measure it. And [my classmate] was like oh, let me do that, and I was like oh, okay. ...It hurts. Because, you know, they don't really 
know if you know [the answer] they just assume you won't because of your ethnicity. These data examples illustrate that cultural stereotypes related to race-ethnicity, gender, and sexuality that emanate from the macro-context are manifested in adolescents' friendships through instances of peer discrimination (Niwa, 2012; Niwa et al., 2014; Rogers \& Way, 2015).

\section{Identity Development}

The second way that we observe the impact of stereotypes on adolescents' friendships is via identity processes. Adolescents are preoccupied with who they are in the eyes of others (Erikson, 1968), and friends are a captive audience, mostly because adolescents spend much of their free time in the company of peers (Blyth, Hill, \& Thiel, 1982; Brown, 2004;

Csikszentmihalyi \& Larson, 1984). For racial-ethnic minority youth, the normative task of identity development is intensified as they work to cultivate a positive sense of self in the face of negative cultural expectations and stereotypes (García Coll et al., 1996; Spencer, 1995). Macrolevel stereotypes are like "social mirrors" that color how youth view themselves in the social world (Suarez-Oroczo, 2004). Prior research shows that adolescents may respond to stereotypes by positioning themselves in alignment with the stereotypes, endorsing or reinforcing society's expectations for them, or they may actively position themselves in opposition to them, challenging the stereotypes and defining themselves as distinct from the stereotypes (Anyon, 1984; Spencer et al., 1997; Rogers, 2012; Way \& Rogers, 2014; Way et al., 2008).

In our prior studies we find that the desire not to be seen as a stereotype - and to resist stereotypes - dominates the identity narratives of racial-ethnic minority adolescents (Way et al., 2008, 2013; Way \& Rogers, 2014). African American youth in our studies, for example, did not want to be seen as "dumb," "lazy," and "bad", Chinese American youth did not want to be seen as "nerdy" or "weak," and Dominican American youth did not want to be seen as "gangsters" 
and "unsuccessful" (Way et al., 2013). Moreover, we find that how youth position themselves relative to these stereotypes - their identities - influences their friendship opportunities and the quality of those friendships. For example, Rogers (2012) found that Black boys who positioned themselves in opposition to racial and gender stereotypes, challenging cultural norms that frame them as emotionally stoic and independent, emphasized the value and importance of friendships; they had "best friends," and shared stories of disclosure and intimacy with their friends (markers of high friendship quality). For example, asked if friendship is important, Brandon (AfricanAmerican) said: "Yeah. Because like say for instance, you need something, like a helping hand or something, it's important. If you don't have no friends you be like, 'man it takes two to do this job,' then you just be out of luck." Monte (African-American), similarly responded: "Yeah, friendship is important through your whole life. Because without friends, you would be lonely, you wouldn't have nobody to talk to." In describing his relationship with his best friend, Monte, said: "it's real, real close. You just feel it. That's how I feel around Terrance." In contrast to racial and gender norms that position African American males as unemotional and autonomous, boys who constructed their identities in opposition to racial and gender stereotypes revealed their vulnerability and desire for intimacy and interdependence with friends.

These stories of desire for intimate friendships were contrasted with boys who aligned themselves more with mainstream racial and gender stereotypes that position Black males as unemotional, hyper aggressive, and hypersexual (Rogers, 2012). For boys in this identity pattern, friends were seen as "acquaintances" and having a best friend was neither desirable nor necessary. As Steven (African-American) explained, "there's no reason to [have a best friend]. Basically everybody is the same." That is, boys' friendships as interchangeable and dispensable. For boys who accommodated to stereotypes, friends were not seen as intimate "chumships" 
(Sullivan, 1954) but distant associates to "kick it with," or "who got your back when you in trouble", or "just like to have fun." Thus, stereotypes about how boys should be shaped boys' identities, which in turn informed the quality and intimacy of their friendships (Rogers, 2012).

Other research on adolescent boys' friendships also suggests that when boys position themselves in opposition to gender stereotypes - specifically, challenging the need to be autonomous and emotionally stoic, they are more likely to express emotional vulnerability in their friendships and describe their friendships as supportive (Cunningham \& Meunier, 2004; Chu, 2004; Santos, 2010; Way, 2011; Way et al., 2014). For example, Cunningham and Meunier (2004) found an inverse relation between vulnerability/relational intimacy and masculine bravado attitudes among African American males, such that boys with less bravado reported greater desire for intimacy and self-disclosure in their friendships. Santos (2010) similarly finds that adolescent boys with higher levels of adherence to norms of masculinity report lower levels of friendship quality (in terms of support) over time. In this way, friendship can function as a micro-context where youth are supported to challenge cultural expectations and resist negative stereotypes about who they "should be" (Chu, 2004; Gilligan, 2011; Nasir, 2011; Way, 2011). The Chinese-American high school students in Way's studies (Niwa et al., 2011) who often experienced peer discrimination responded by deliberately defining themselves as strong and tough, resisting the stereotype that Chinese people are weak and passive:

People are under the impression that I'm passive. Beginning of high school there were a few kids who picked on me, just pushed me out of the way. Thought I was a quiet kid and you know, I just had to do something to display to them that I'm not somebody you just fuck with.

Ronald (African-American) also explained that although others may expect him to conform to 
the stereotype "to act tough to be accepted or be in a gang," he positions himself differently:

I know that like if you are about to get in a fight and you walk away from it, that's the right thing, but some, other people, they'll say you're lame for leaving, 'you're scared,' 'you're a punk,' all of that. And I think that's why people try to act tough all the time.

But it doesn't matter, I just walk away.

Ronald recognizes that the stereotype to "act tough" among friends is not the "right thing" and cultivates an identity that counters the cultural expectation ("I just walk away"). Such resistance within the context of friendships offers adolescents alternative pathways to form positive friendships. The adolescents across our studies were actively constructing their identities in response to cultural stereotypes about who they are and should be, and where they positioned themselves within this cultural narrative impacted their friendships. Taking up identities that challenge these macro-level stereotypes shifted the landscape of adolescents' friendships.

\section{UNIVERSAL AND CULTURAL-SPECIFIC FINDINGS}

Our data allows us to see how the macro-context of stereotypes shapes relationships across a range of contexts. Friendships, and relationships more broadly, appear to act as a conduit for the macro-context, a mechanism through which macro-level processes of racism, sexism, and homophobia, are manifested in the proximal experiences of relationships between individuals. In this chapter, we focused on peer relationships among racially-ethnically diverse American youth, as an example of this link between the macro and micro-context. The link between macro- and micro-, however, can be realized on multiple levels of relationships and thus, these processes may occur within the family, with teachers, and in community/neighborhood relationships. Similarly, the relationship with the self, or identity, is shaped by stereotypes. Long ago, Erikson (1968) argued that self-processes laid the foundation for relational processes. Our 
data show that this does not occur in a vacuum, but identities are affected by cultural stereotypes that, in turn, shape relational pathways. Thus, the dynamic bidirectional relationship between self and other are inextricable from the macro-context of culture and this interaction likely reflects universal truths about human development rather than simply culturally specific findings.

Our research findings are based on studies with adolescents in both racially-ethnically diverse settings and a racially homogeneous setting. In diverse settings, adolescents interface with youth of different backgrounds and are afforded the opportunity to use and experience stereotypes, thus increasing for example the likelihood of peer discrimination across racial-ethnic groups. Our research, however, also includes data from a homogenous context - an all-Black, all-male high school. In this context, we also observed how stereotypes function to stratify adolescents' friendships. Thus, it seems that the process through which the macro-context of stereotypes impacts the micro-context of friendships may be evident in both diverse and homogenous contexts, though the dimensions of judgment and value may differ. For example, in racially diverse schools, adolescents discussed race-ethnic stereotypes and discrimination in their friendships. But, in the all-male school context, adolescents used gender and sexuality stereotypes (infused with race) to discriminate and exclude their peers. That is, the context may activate particular stereotypes, but the process is likely present across settings. For example, in a predominately White private school, adolescents' friendships may be structured along the lines of social-class stereotypes more than race-ethnicity. From this position, the process of macrolevel impacting adolescents' friendships via stereotypes may indeed be a universal phenomenon.

\section{IMPLICATIONS AND FUTURE DIRECTIONS}

The goal of this chapter was to highlight the impact of the macro-context on adolescents' friendships by examining how cultural stereotypes shape the friendships' of racial-ethnic 
minority adolescents. Our studies found that two paths of influence are peer discrimination and identity processes. The ecological perspective underscores how social position variables (e.g., race/ethnicity, gender, sexuality) and social processes (e.g., discrimination) shape adolescents' perceptions and responses to themselves and those around them. Our data reveal how stereotypes simultaneously inform self-processes (i.e., identity) and relational processes (i.e., friendships), and placing adolescents' friendships in an ecological paradigm underscores the intersecting nature of these developmental processes.

The racial-ethnic differences we found in our studies were in the content of the stereotype rather than the process of impact. For example, the Chinese-American adolescents in our studies, for example, were stereotyped as weak and passive and as a result were victimized by peers. In contrast, the African-American adolescents, who were stereotyped as tough and aggressive, rarely endured such threats from peers. The significance of this "ethnic difference" is not only that one group is harassed more than another but also in revealing the ways in which negative stereotypes structure the friendship experiences and opportunities of adolescents within each ethnic group. At the same time, our studies make evident that stereotypes and ecologies are not only relevant for racial-ethnic minority adolescents but for all adolescents as all adolescents are stereotyped regarding some aspect of their social identities. In addition, stereotypes are relational and formed in response to one another (Nasir \& Shah, 2011; Way, 2011; Way et al., 2008; Way et al., 2013) and thus the stereotypes that structure the friendships of ethnic minority youth simultaneously inform those of the ethnic majority and vice versa. If, for example, being aggressive and a troublemaker is the stereotype that defines the friendships of Black boys then not being aggressive and delinquent (i.e., pro-social and compliant) becomes the framework for the friendships of White boys (e.g., Dishion \& Piehler, 2009) and vice versa. Examining the 
ecological context of friendships can deepen the study of friendships among racial-ethnic majority adolescents because it recognizes that the macro-context of stereotypes positions youth in ways that differentially shape their friendship opportunities and experiences and influences the quality of and choices made by adolescents.

Although we know from an extensive literature that friendships are a robust and important predictor of adolescent outcomes (e.g., Rubin et al., 2009), this chapter contributes to our understanding the factors that shape friendships themselves. Given the relevance of friendships to healthy youth adjustment, understanding the factors that undermine positive, high quality friendships is critical for understanding how to foster resistance to those factors so that positive adjustment occurs (Way \& Rogers, forthcoming). Our findings suggest that stereotypes can pose a critical barrier to positive peer relationships especially across racial-ethnic groups. Thus, helping youth cultivate friendships that counteract negative messages that emanate from the larger cultural environment is critical. If we take seriously that stereotypes form the context of friendships, it becomes evident why youth often gravitate toward same-ethnic peers while cross-ethnic friendships are rare and less stable (e.g., McGill et al., 2012; Tatum, 1997). Increasing cross-ethnic friendships is not merely about the "opportunity" for interaction with peers of other racial-ethnic groups (e.g., Moody, 2001), but also, perhaps more critically, about challenging longstanding stereotypes that interfere with positive peer interactions across racialethnic groups. This process has significant implications for interventions and programs designed to support positive youth development.

Friendships are essential in the lives of adolescents as they create a space for selfexploration and transformation. And these friendships are intricately woven into the fabric of the environments in which they reside. As so eloquently described by Erikson (1968) many decades 
ago, individual development is a constant interplay between the psychological and the social, the developmental and the historical. Friendships that exist in the micro-contexts of adolescents' lives are indelibly shaped by the larger macro-contexts, specifically the stereotypes that envelope and give meaning to those micro-contexts. Negative stereotypes threaten to undermine adolescents' friendships by fostering divisions and perpetuating inequality. At the same time, however, friendships offer an opportunity and space for social change when youth challenge negative cultural norms, expectations and stereotypes in their everyday relationships. 


\section{References}

Anyon, J. (1984). Intersections of gender and class: Accommodation and resistance by workingclass and affluent females to contradictory sex role ideologies. Journal of Education, 166, 25-48

Azmitia, M., \& Cooper, C. R. (2001). Good or bad? Peer influences on Latino and European American adolescents' pathways through school. Journal of Education for Students Placed at Risk, 6, 45-71. doi:10.1207/S15327671ESPR0601-2_4

Azmitia, M., Ittel, A., \& Brenk, C. (2006). Latino-Heritage Adolescents' Friendships. In X. Chen, D. C. French, B. H. Schneider (Eds.), Peer relationships in cultural context (pp. 426-451). New York, NY: Cambridge University Press. doi:10.1017/CBO9780511499739.019

Berndt, T. J. (2004). Children's friendships: Shifts over a half-century in perspectives on their development and their effects. Merrill-Palmer Quarterly, 50, 206-223. doi:10.1353/mpq.2004.0014

Blyth, D. A., Hill, J. P., \& Thiel, K. S. (1982). Early adolescents' significant others: Grade and gender differences in perceived relationships with familial and nonfamilial adults and young people. Journal of Youth And Adolescence, 11, 425-450. doi:10.1007/BF01538805

Bond, M. (2013). Why are you like you are? New Scientist Magazine, The Great Illusion of the Self 217, pp.41-43. Doi:10.1016/S0262-4079(13)60504-7

Bowlby, J. (1969). Attachment and loss, Vol.1: Attachment (2nd Ed.). New York: Basic Books.

Bronfenbrenner, U. (1979). Contexts of child rearing: Problems and prospects. American Psychologist, 34, 844-850. doi:10.1037/0003-066X.34.10.844

Bronfenbrenner, U., \& Morris, P. A. (1998). The ecology of developmental processes. In W. Damon, R. M. Lerner (Eds.), Handbook of child psychology: Vol 1: Theoretical models of 
human development (5th ed.) (pp. 993-1028). Hoboken, NJ: John Wiley \& Sons Inc.

Bukowski, W. M., Newcomb, A. F., \& Hartup, W. W. (1996), The company they keep:

Friendship in childhood and adolescence. New York, NY: Cambridge University Press.

Carter, P. L. (2006). Straddling Boundaries: Identity, Culture, and School. Sociology Of

Education, 79, 304-328. doi:10.1177/003804070607900402

Cauce, A. M. (1986). Social networks and social competence: Exploring the effects of early adolescent friendships. American Journal Of Community Psychology, 14, 607-628. doi:10.1007/BF00931339

Chu, J. Y. (2004). A relational perspective on adolescent boys' identity development. In N. Way, \& J. Y. Chu (Eds.), Adolescent boys: Exploring diverse cultures of boyhood. (pp. 78104). New York, NY: New York University Press.

Chu, J. Y. (2014). When boys become boys: Development, relationships, and masculinity. New York, NY: New York University Press.

Chua, P., \& Fujino, D. C. (2008). Negotiating new Asian-American masculinities: Attitudes and gender expectations. The Journal of Men's Studies, 7, 391-413. doi:

Crockett, L., Losoff, M., \& Petersen, A. C. (1984). Perceptions of the peer group and friendship in early adolescence. The Journal Of Early Adolescence, 4, 155-181. doi: $10.1177 / 0272431684042004$

Crosnoe, R., Cavanagh, S., \& Elder, G. J. (2003). Adolescent friendships as academic resources: The intersection of friendship, race, and school disadvantage. Sociological Perspectives, 46, 331-352. doi:10.1525/sop.2003.46.3.331

Csikszentmihalyi, M. \& Larson, R. (1984). Being adolescent: Conflict and growth in the teenage years. New York, NY: Basic Books. 
Davis, J. E. (2001). Transgressing the masculine: African American boys and the failure of schools. In W. Martino, \& B. Meyenn (Eds.), What about the boys?: Issues of masculinity in schools. (pp. 140-153). Maidenhead, BRK, England: Open University Press.

de Waal, F. (2006). Primates and philosophers: How morality evolved. Princeton, NJ: Princeton University Press

Dishion, T. J., \& Piehler, T. F. (2009). Deviant by design: Peer contagion in development, interventions, and schools. In K. H. Rubin, W. M. Bukowski, B. Laursen (Eds.), Handbook of peer interactions, relationships, and groups (pp. 589-602). New York, NY: Guilford Press.

Dodge, K., Coie, J., \& Lynam, D. (2006). Aggression and antisocial behavior in youth. In N. Eisenberg (Ed.), Handbook fo child psychology: Vol. 3. Social emotional, and personality development (6 ${ }^{\text {th }}$ ed., pp. 719-788). Hoboken, NJ: Wiley.

DuBois, D. L., \& Hirsch, B. J. (1990). School and neighborhood friendship patterns of Blacks and Whites in early adolescence. Child Development, 61, 524-536. doi:10.2307/1131112

Eccles, J. S., \& Roeser, R. W. (1999). School and community influences on human development. In M. H. Bornstein, M. E. Lamb (Eds.), Developmental psychology: An advanced textbook (4th ed.) (pp. 503-554). Mahwah, NJ,: Lawrence Erlbaum Associates Publishers.

Fordham, S. (1993). 'Those loud Black girls': (Black) women, silence, and gender 'passing' in the academy. Anthropology \& Education Quarterly, 24, 3-32. doi:10.1525/aeq.1993.24.1.05x1736t

Fordham, S., \& Ogbu, J. U. (1986). Black students' school success: Coping with the 'burden of acting White.'. The Urban Review, 18, 176-206. doi:10.1007/BF01112192

Furman, W. (1996). The measurement of friendship perceptions: Conceptual and methodological 
issues. In W. M. Bukowski, A. F., Newcomb, \& W. W. Hartup (Eds.), The company they keep: Friendship in childhood and adolescence (pp. 41-65). New York, NY: Cambridge University Press.

García-Coll, C. Lamberty, G. Jenkins, R., Pipes McAdo, H., Crnic, K., Wasik, B. H., \& et al. (1996). An intergrative model for the study of developmental competencies in minority children. Child Development, 67, 1891-1914.

García-Coll, C. G., \& Szalacha, L. A. (2004). The Multiple Contexts of Middle Childhood. The Future Of Children, 14, 81-97. doi:10.2307/1602795

Ghavami, N., \& Peplau, L. A. (2013). An intersectional analysis of gender and ethnic stereotypes: Testing three hypotheses. Psychology Of Women Quarterly, 37, 113-127.

Gilligan, C. (1982). In a different voice: Psychological theory and women's development. Boston, MA: Harvard University Press.

Gilligan, C. (2011). Joining the resistance. Oxford, England: Polity Press.

Gordon, C., \& Gergen, K. J. (1968). The self in social interaction: I. Classic \& contemporary perspectives.

Graham, S., Taylor, A. Z., \& Ho, A. Y. (2009). Race and ethnicity in peer relations research. In K. H. Rubin, W. M. Bukowski, B. Laursen (Eds.), Handbook of peer interactions, relationships, and groups (pp. 394-413). New York, NY: Guilford Press.

Gupta, T., \& Sirin, S. (2010). The social development of immigrant children and their families. Paper presented at the NYU Developmental Colloquia. New York, NY.

Hallinan, M. T., \& Teixeira, R. A. (1987). Opportunities and constraints: Black-White differences in the formation of interracial friendships. Child Development, 58, 13581371. doi:10.2307/1130627 
Hallinan, M. T., \& Williams, R. (1987). The stability of students' interracial friendships. American Sociological Review, 52, 653-664.

Hamm, J. V., Brown, B. B., \& Heck, D. J. (2005). Bridging the Ethnic Divide: Student and School Characteristics in African American, Asian-descent, Latino, and White Adolescents' Cross-Ethnic Friend Nominations. Journal Of Research On Adolescence, 15, 21-46. doi:10.1111/j.1532-7795.2005.00085.x

Hartup, W. W. (1996). The company they keep: Friendships and their developmental significance. Child Development, 67, 1-13. doi:10.2307/1131681

Hinde, R. A. (1987). Individuals, relationships and culture: Links between ethology and the social sciences. Cambridge, UK: Cambridge University Press.

Horvat, E. M., \& O'Connor, C. (2006). Beyond acting White: Reframing the debate on Black student achievement. New York: Rowman \& Littlefield Publishers.

Hrdy, S. B. (2009). Mothers and others: The evolutionary origins of mutual understanding. Cambridge, MA: Harvard University Press.

Jia, Y., Way, N., Ling, G., Yoshikawa, H., Chen, X., Hughes, D., \& ... Lu, Z. (2009). The influence of student perceptions of school climate on socioemotional and academic adjustment: A comparison of Chinese and American adolescents. Child Development, 80, 1514-1530. doi:10.1111/j.1467-8624.2009.01348.x

Kao, G., \& Joyner, K. (2004). Do race and ethnicity matter among friends? Activities among interracial, interethnic, and intraethnic adolescent friends. The Sociological Quarterly, 45, 557-573. doi:10.1111/j.1533-8525.2004.tb02303.x

Lee, S. J. (1994). Behind the model-minority stereotype: Voices of high- and low-achieving Asian American students. Anthropology \& Education Quarterly, 25, 413-429. 
doi:10.1525/aeq.1994.25.4.04x0530j

Lei, J. L. (2003). (Un) Necessary Toughness?: Those" Loud Black Girls" and Those" Quiet Asian Boys". Anthropology \& Education Quarterly, 34, 158-181.

Lesko, N. (2001). Act your age! A cultural construction of adolescence. New York, NY: Routledge Falmer.

López, N. (2003). Hopeful girls, troubled boys: Race and gender disparity in urban education. New York, NY: Routlege.

Luther, S. \& McMahon, T. (1996). Peer reputation among inner-city adolescents: Structure and correlates. Journal of Research on Adolescence, 6, 581-603.

McGill, R. K., Way, N., \& Hughes, D. (2012). Intra- and interracial best friendships during middle school: Links to social and emotional well-being. Journal of Research on Adolescence, 22, 722-738.

Moody, J. (2001). Race, school integration, and friendship segregation in America. American Journal Of Sociology, 107, 679-716. doi:10.1086/338954

Mouw, T., \& Entwisle, B. (2006). Residential Segregation and Interracial Friendship in Schools. American Journal Of Sociology, 112, 394-441. doi:10.1086/506415

Nasir, N. S. (2011). Racialized identities: Race and achievement among African American youth. Stanford, CA: Stanford University Press.

Nasir, N. I. S., \& Shah, N. (2011). On defense: African American males making sense of racialized narratives in mathematics education. Journal of African American Males in Education, 2, 24-45.

Niwa, E. Y. (2012). The impact of ethnic and racial discrimination on the social and psychological adjustment of early adolescents: A mixed-method, longitudinal study (Doctoral Dissertation) . Dissertation Abstracts International: Section B: The Sciences 
and Engineering, 73,(10-B), 3511454.

Niwa, E.Y., Way, N., \& Hughes, D. (2014). Trajectories of ethnic-racial discrimination among ethnically diverse early adolescents: Associations with psychological and social adjustment. Child Development, 85(6), 2339-2354.

Niwa, E. Y., Way, N., Qin, D. B., \& Okazaki, S. (2011). Hostile hallways: Asian American adolescents' experiences of peer discrimination in school. In F. T. L. Leong, L. Juang, D. B. Qin, \& H. E. Fitzgerald (Eds.) Asian American and Pacific Islander children and mental health. Vol I: Development and context (pp. 193-219). CA: Praeger.

Noguera, P. A. (2008). The trouble with black boys:... And other reflections on race, equity, and the future of public education. San Francisco, CA: John Wiley \& Sons.

Osterman, K. F. (2000). Students' need for belonging in the school community. Review Of Educational Research, 70, 323-367. doi:10.2307/1170786

Pascoe, C. J. (2007). Dude, you're a fag: Masculinity and sexuality in high school. Berkeley, CA: University of California Press.

Pew Research Center (2011, March 30). "Minorities Account for Nearly All U.S. Population Growth." http://www.pewresearch.org/daily-number/minorities-account-for-nearly-all-us-population-growth/ Retrieved online January 4, 2015.

Pew Research Center (2014, July 8). "A view of the future through kindergarten demographics." http://www.pewresearch.org/fact-tank/2014/07/08/a-view-of-the-future-throughkindergarten-demographics/ Retrieved online January 4, 2015.

Rodkin, P. C., Farmer, T. W., Pearl, R., \& Van Acker, R. (2000). Heterogeneity of popular boys: Antisocial and prosocial configurations. Developmental Psychology, 36, 14-24. doi:10.1037/0012-1649.36.1.14

Rogers, L. O. (2012). Young, Black, and male: Exploring the intersections of racial and gender 
identity in an all-Black, all-male high school. Available from ProQuest Dissertation Abstracts (UMI No. 10197).

Rogers, L. O., \& Way, N. (2015). "I have goals to prove all those people wrong and not fit into any one of those boxes": Paths of resistance among Black adolescent males. Manuscript accepted for publication in Journal of Adolescent Research.

Rosenbloom, S., \& Way, N. (2004). Experiences of discrimination among African American, Asian American, and Latino adolescents in an urban high school. Journal of Youth and Society.

Rubin, K. H., Bukowski, W. M., \& Laursen, B. (Eds.). (2009). Handbook of peer interactions, relationships, and groups. Guilford Press.

Savin-Williams, R. C., \& Berndt, T. J. (1990). Friendship and peer relations. In S. S. Feldman, G. R. Elliott (Eds.), At the threshold: The developing adolescent (pp. 277-307). Cambridge, MA: Harvard University Press.

Shek, Y. L. (2006). Asian American Masculinity: A Review of the Literature. The Journal Of Men's Studies, 14, 379-391. doi:10.3149/jms.1403.379

Spencer, M. B. (1995). Old and new theorizing about African American youth:A phenomenological variant of ecological systems theory. In R. L. Taylor (Ed.), Black youth: Perspectives on their status in the United States (pp. 37-69). Westport, CT: Praeger.

Spencer, M. B., Dupree, D., \& Hartmann, T. (1997). A phenomenological variant of ecological systems theory (PVEST): A self-organization perspective in context. Development And Psychopathology, 9, 817-833. doi:10.1017/S0954579497001454

Stangor, C., \& Schaller, M. (1996). Stereotypes as individual and collective representations. In C. N. Macrae, M. Hewstone, \& C. Stangor (eds). Foundations of Stereotypes and 
Stereotyping. (pp. 3-37). New York: Guilford Press.

Steinberg, L. \& Monahan, K. (2007). Age differences to peer influence. Developmental Psychology, 43, 1531-1543.

Stevenson, H. J. (1997). Missed, Dissed, and Pissed': Making Meaning of Neighborhood Risk, Fear and Anger Management in Urban Black Youth. Cultural Diversity And Mental Health, 3, 37-52. doi:10.1037/1099-9809.3.1.37

Suárez-Orozco, C. (2004). Formulating Identity in a Globalized World. In, Globalization: Culture and education in the new millennium (pp. 173-202). Berkeley, CA: University of California Press.

Sullivan, H. S. (1953). The interpersonal theory of psychiatry. New York, NY: W W Norton \&Co.

Tatum, B. D. (2003). "Why are all the Black kids sitting together in the cafeteria?": and other conversations about race. New York, NY: Basic Books.

Trevarthen, C. (1979). Communication and cooperation in early infancy: A description of primary intersubjectivity. In M. Bullowa (Ed.) Before speech: The beginning of interpersonal communication, 321-347. New York, NY: Cambridge University Press.

Updegraff, K. A., McHale, S. M., Crouter, A. C., and Kupanoff, K. (2001). Parents' involvement in adolescents' peer relationships: A comparison of mothers' and fathers' roles. $J$. Marriage Fam. 63: 655-668.

Way, N. (2011). Deep secrets: Boys' friendships and the crisis of connection. Cambridge, MA: Harvard University Press.

Way, N., Becker, B. E., \& Greene, M. L. (2006). Friendships among black, Latino, and Asian American adolescents in an urban context . In L. Balter \& C. S. Tamis-LeMonda (Eds.), Child psychology: A handbook of contemporary issues (2nd ed.) (pp. 415 - 443). New 
York and Hove, East Sussex: Psychology Press.

Way, N., \& Chen, L. (2000). Close and general friendships among African American, Latino, and Asian American adolescents from low-income families. Journal of Adolescent Research, 15, 274-301. doi:10.1177/0743558400152005

Way, N., \& Greene, M. L. (2006). Trajectories of Perceived Friendship Quality During Adolescence: The Patterns and Contextual Predictors. Journal Of Research On Adolescence, 16, 293-320. doi:10.1111/j.1532-7795.2006.00133.x

Way, N., Hernández, M. G., Rogers, L. O., \& Hughes, D. L. (2013). 'I'm not going to become no rapper": Stereotypes as a context of ethnic and racial identity development. Journal of Adolescent Research, 28, 407-430. doi: 10.1177/0743558413480836

Way, N. \& Rogers, L. O. (forthcoming). Resistance to dehumanization: A developmental process. Invited chapter in N. Nasir, C. Wainryb, \& E. Turiel (Eds.) Jean Piaget Society. Cambridge, UK: Cambridge University Press.

Way, N., \& Rogers, L. O. (2014). “[T]hey say Black men won't make it, but I know I'm gonna make it": Identity development in the context of cultural stereotypes. Chapter in M. Syed \& K. McLean (Eds.) Oxford handbook of identity development (pp. 269-285). New York, NY: Oxford University Press.

Way, N., Santos, C., Niwa, E. Y., \& Kim-Gervey, C. (2008). To be or not to be: An exploration of ethnic identity development in context. New directions for child and adolescent development, 2008, 61-79. DOI: 10.1002/cd.216

Way, N., \& Silverman, L. R. (2011). The quality of friendships during adolescence. In P. K. Kerig, M. S. Schulz, \& S. T. Hauser (Eds), Adolescence and beyond: Family processes and development, 91-112. New York, NY: Oxford University Press. 